\title{
An investigation of assumptions made in estimating genetic parameters and predicting genetic gain in a Eucalyptus nitens breeding programme in South Africa
}

\author{
T-L Swain ${ }^{1}$, SD Verryn ${ }^{2}$, MD Laing ${ }^{3}$ \\ ${ }^{1}$ Institute for Commercial Forestry Research, PO Box 100281, Scottsville, Pietermaritzburg 3209, South Africa. \\ Tammy.Swain@icfr.ukzn.ac.za (corresponding author) \\ Ph: 27-33-3862314 Fax: 27-33-3868905 \\ ${ }^{2}$ Department of Genetics, Forestry and Agricultural Biotechnology Institute (FABI), University of Pretoria, Private Bag X20, Hatfield, \\ Pretoria 0028, South Africa and Creation Breeding Innovations, 75 Kafue St, Lynnwood Glen, 0081, South Africa. \\ ${ }^{3}$ School of Agricultural Earth and Environmental Sciences (SAEES), University of KwaZulu-Natal, PO Box X01, Scottsville, 3209, \\ South Africa.
}

\begin{abstract}
It is important to have an understanding of the population genetics and validity of the pertinent underlying assumptions of a species in order to design an effective breeding strategy. In a South African breeding population of Eucalyptus nitens, various scenarios investigating a range of assumptions were developed and used to predict genetic gain in the F2. These were compared with realised gains achieved in a series of genetic gain trials. In the two scenarios using firstly, actual flowering for family (provenance) and, secondly, estimated flowering after $30 \%$ roguing of poor families, a coefficient of relationship of 0.33 resulted in predictions closest to realised gain on average. The statistical information suggested that outcrossing in the seed orchards was greater than $80 \%$. Indications were that the effects were additive, and that very little or no heterosis had occurred, due to the still significant provenance effects and the lack of provenance rank changes in the F2.
\end{abstract}

The custom of assuming a degree of inbreeding (and using a coefficient of relationship of 0.33 ) and of including provenance effects in the models on average resulted in genetic gain predictions which were very similar to the realised genetic gains in this population of Eucalyptus nitens. 


\section{Keywords}

E. nitens, genetic parameters, coefficient of relationship, outcrossing, provenance effects

\section{Introduction}

A good understanding of the population genetics and underlying assumptions of a species are important for designing breeding strategies (Tibbits and Hodge 1998). Eucalyptus nitens is an important commercial cold tolerant eucalypt (CTE) species, grown primarily for pulp and paper production in the summer rainfall regions of South Africa. Currently there are no suitable alternative commercial eucalypt species to E. nitens in South Africa for sites prone to moderate frost and heavy snowfalls (Gardner and Swain 1996). There is considerable variation for several growth, reproductive and wood property traits within the species in South Africa, which is based primarily on Australian provenance origin (Swain 2013). This variation provides potential for genetic improvement, and it is important that an appropriate advanced generation breeding strategy be developed for improvement of E. nitens.

Several studies have been done to estimate genetic parameters in E. nitens (Gea et al. 1997; Johnson 1996; King and Wilcox 1988; Tibbits and Hodge 1998; Whiteman et al. 1992), with some research into the factors affecting these estimates, i.e., panmixis (Grosser et al. 2010; Tibbits 1989), outcrossing rates (Gea et al. 1997; Grosser et al. 2010; Moncur et al. 1995), self-incompatibility and inbreeding (Hardner and Tibbits 1998, Pound et al. 2003). However, there is little known about the underlying assumptions in the South African populations of E. nitens, and there is some concern about the impact that poor and erratic flowering, and subsequent seed production, of the species in South Africa (Gardner 2003) may have on genetic gain. In addition, the poor flowering may violate some of the basic assumptions in parameter estimation and genetic gain prediction, such as occurrence of panmixis, absence of non-additive effects, no correlation between flowering and growth, and may affect the coefficient of relationship used.

Statistical analysis of several F1 and F2 E. nitens trials run by the Institute for Commercial Forestry Research (ICFR) in South Africa has led to the development of estimates for genetic parameters and of 
juvenile-mature and trait-trait genetic correlations, as well as an indication of the presence/absence of genotype by environment interaction (Swain 2013; Swain et al. 2013b).These have been invaluable in determining the breeding potential of the E. nitens population, selection of superior families and individuals, as well as informing the breeding strategy for the species. Genetic gain trials allowed for comparison of realised gain in the F2 with predicted genetic gain from the F1 (Swain 2013), and this provides an opportunity to assess the performance of the quantitative predictions using our underlying assumptions in the F1.

There are several assumptions made in the predictions of genetic gains which, if incorrect, may cause inaccuracy in predictions using deterministic methodology (Verryn et al. 2000b):

1) The assumption of the coefficient of relationship $(c r)=0.33$ to allow for the presence of full-sibs within the open-pollinated families, and that at least some inbreeding occurs (Snedden et al. 2007; Squillace 1974).

2) The assumption of $>70 \%$ outcrossing between eucalypt seed orchard trees. Moncur et al. (1995) estimated that outcrossing was at a level of $75 \%$ in an E. nitens seed orchard, and Pound et al. (2003) found that levels of self-incompatibility in E. nitens ranged from 25.8 to 93.6\%. The species demonstrates preferential outcrossing and appears to have a late-acting selfincompatibility system operating to reduce the production of selfed seed (Pound et al. 2003; Tibbits 1989). The assumption of $>70 \%$ outcrossing made by many authors (Butcher and Williams 2002; Grosser et al. 2010; Hodge et al. 1996; Moncur et al. 1995; Moran et al. 1989), may not be true of these F1 E. nitens seed orchards, due to poor flowering.

3) The assumption that flowering and mating is random, and that panmictic pollination is occurring, i.e., that all individuals have equal opportunities to mate with any other individual (Hodge and White 1993).

i) Asynchronous flowering has been shown to exist between eucalypt provenances (Jones 2002; Moncur and Boland 2001; Tibbits 1989; Volker et al. 1990), indicating that this assumption may not be correct. However, these flowering windows do overlap (Gardner 2003; Jones 2002), which may allow for panmictic pollination some of the time. In addition to 
asynchronocity, flowering in E. nitens is subject to seasonal influences (Gardner and Bertling 2005; Jones 2002; Moncur and Hasan 1994; Tibbits 1989) and, as the stability, or greater influence, of female effects in reproductive success in some eucalypts has been noted (Leal and Cotterill 1997; Suitor et al. 2009; Tibbits 1989), it is possible that only a few effective males may contribute to pollination of all the other trees in a seed orchard (Hodge et al. 1996; Suitor et al. 2009; Swain et al. 2013a). Conversely, pollen from a few heavy-flowering individuals may have too large a genetic influence on adjacent female trees (Moncur and Boland 2001). Grosser et al. (2010) also found that the parental contribution to progeny varied amongst clones in an E. nitens clonal seed orchard, suggesting that panmictic pollination was not occurring.

ii) Actual selection intensity - in reality, stratified selection based on flowering could have taken place in the ICFR seed orchards, as flowering of individual trees ranged from 15 to $<50 \%$ in the year prior to seed collections (Swain et al. 2013a). This means that up to ten trees may have contributed seed from some families and as little as one tree contributed from other families, i.e., the selection intensity in the orchard could have been higher than the figures used in the predictions, resulting in higher realised genetic gains.

4) The assumption that there is no correlation between flowering and growth, i.e., flowering individuals would not be selected against due to their growth, and vice versa. Varghese et al. (2009) found contrasting trends in their studies on E. camaldulensis and E. tereticornis in India. These authors found a negative genetic correlation between flowering and outstanding growth performance in unimproved provenances in E. camaldulensis, but no such correlation was found in an improved seed orchard of E. teretecornis. Although there are currently no published results on such studies on E. nitens in South Africa, Gardner (pers comm ${ }^{1}$ ) did not find any correlations between flowering and growth in flowering studies in E. nitens, nor has Jones (pers comm ${ }^{2}$ ) found any strong correlations in E. nitens seed orchards.

5) The assumption of the absence of non-additive effects such as inbreeding depression or heterosis, the latter as a result of mixing of provenances by outcrossing of all families in the F1. It has been

\footnotetext{
${ }^{1}$ Gardner RAW. 2012. Institute for Commercial Forestry Research, Pietermaritzburg, PO Box 100281, Scottsville, 3209, SOUTH AFRICA

${ }^{2}$ Jones W. 2013. Shaw Research Centre, Tweedie, PO Box 473, Howick, 3290, SOUTH AFRICA
} 
assumed that variance is additive in this E. nitens breeding population, with negligible nonadditive effects, as has been found in other studies on the species (Hamilton et al. 2008; Hodge et al. 1996), but if non-additive effects were playing a role, the predictions of genetic gain would be overestimated due to inflation of narrow-sense heritability estimates (Bush et al. 2011; Hodge et al. 1996).

Therefore, to determine which assumptions best fit the ICFR E. nitens populations for the estimation of genetic parameters in the F1, several scenarios of predicted genetic gain were developed from the F1, and compared with the gains realised from genetic gain trials (F2). Recently, similar studies have been done on stand volume in E. globulus (Callister et al. 2013), and on E. cladocalyx, incorporating molecular markers to calculate inbreeding rates and coefficients of relationship (Bush et al. 2011). This study will also indicate whether there are important digressions from the assumptions made in the F1 study (Swain et al. 2013b), and whether the E. nitens breeding strategy needs to be adapted to take these into account.

\section{Material and Methods}

Eight $\mathrm{F} 1$ provenance-progeny trials comprising E. nitens seedlots imported from Australia were established in the summer rainfall region of South Africa during the 1980's and 1990's. Details of these F1 trials, statistical analysis thereof, estimation of genetic parameters for the F1 and predicted gain for the F2 can be found in Swain et al. (2013b). Both the estimation of genetic parameters in the F1 and predicted gains for the F2 used a coefficient of relationship of 0.33 (Swain et al. 2013b). These trials were subsequently thinned to seed orchards, based on the results of the final measurements, and seed collected over several years to establish progeny trials (F2) of this material (Swain 2013). In addition, three genetic gain trials were established on temperate forestry sites in South Africa early in 2001 to test the improved material (Swain et al. 2013a). The genetic gain trials also allowed for comparison of realised gain in the F2 with predicted genetic gain, as well as the calculation of realised heritabilities in the F1 (Swain 2013).

The realised genetic gains in the F2 were estimated by comparing the average performance of the progeny of a range of improved bulks originating from each of four ICFR F1 seed orchards, i.e., Amsterdam, 
Helvetia, Jaglust and Jessievale, with an F1 bulk (Treatment 22) in the genetic gain trials described by Swain et al. (2013a). The families within each F1 seed orchard were not related by female parent. These realised gains were then compared with the gains predicted from a range of scenarios, testing coefficients of relationship and selection intensities. The authors also investigated the effect of provenance in variance component estimation, i.e., families nested within provenance (family (provenance)) and families across provenances (Swain et al. 2013b), but as this and other studies have shown that across-provenance estimates result in overestimates of additive genetic variance (Brawner and Elizaul 2007; Johnson 1996; Tibbits and Hodge 1998), this scenario was not included in this report. The scenarios investigated were:

1) Coefficient of relationship and outcrossing -

Following the approach of Squillace (1974), and extending his calculations, it has been shown that $30 \%$ selfing gives an average coefficient of relationship among open-pollinated (OP) progeny of 0.4 (Griffin and Cotterill 1988) and 25\% selfing gives an average coefficient of relationship of 0.5 (Hodge et al. 1996). Snedden et al. (2007) assumed a coefficient of relationship of 0.33 in an $E$. grandis study where approximately $20 \%$ inbreeding was found. Extending this approach, the assumed inbreeding of $20 \%$ and the assumed coefficient of relationship of 0.33 may be too low in seed orchards where flowering is poor and pollen trees may be isolated from maternal parents. Although levels of relatedness and inbreeding are not available from ICFR seed orchards until DNA genotyping/genetic marker studies have been completed, percentage of trees flowering has ranged from 15 to $47 \%$ over orchard and year, in terms of the number of individual trees flowering (Swain et al. 2013a), which could decrease genetic gain achieved. Thus this scenario considered an additional higher level of selfing of $25 \%$ (and, by extension, outcrossing rate of $\approx 75 \%$ ) for the family (provenance) parameters estimated above, using a coefficient of relationship of 0.4 as a surrogate for the selfing rate. An assumed selfing rate of $0 \%$ (surrogate $c r=0.25$; assumed outcrossing 100\%) was also included for comparative purposes. Thus the coefficient of relationship can, in effect, be used to correct for relationships closer than half-sib, which have resulted from selfing or related individuals crossing (Bush et al. 2011).

2) Selection intensity - should flowering be poorer in reality, i.e., $40 \%$ flowering, this would decrease the population size from which selections are made, given that the population size was 
less than 400 (Becker 1975), resulting in lower genetic gains. The ICFR seed orchards were rogued of the poorest $30 \%$ of families and each remaining plot thinned so that only the top-ranked tree per plot remained. Thus this scenario is represented by actual flowering that occurred in the ICFR seed orchards the year before seed was collected for the ICFR genetic gain trials, and compared with an assumed $100 \%$ flowering of the remaining $70 \%$ of families after roguing and thinning. Due to the incremental selection applied to the seed orchards, incorporating roguing, thinning and bulking of selected seedlots, computation of the selection intensities was also done in an incremental or phased manner. This scenario was run for the family (provenance) model estimated above, and for the different outcrossing scenarios.

Thus, there were six different scenarios to be compared, as summarised in Table 1.

Genetic gains in the F2 were predicted from the following formula (Verryn et al. 2000, adapted) for the rogued scenarios:

$$
\begin{aligned}
& \Delta G= 0.5\left(\Delta G_{f}\right)+0.5\left(\Delta G_{m}\right), \text { where; } \\
& \Delta G_{f}=\left\lfloor\left(S I_{1} \times c r \times \frac{\sigma_{A}^{2}}{\sigma_{f m}}+S I_{w f} \times \frac{(t-1)}{t} \times(1-c r) \times \frac{\sigma_{A}^{2}}{\sigma_{w f}}\right)+\left(S I_{2} \times c r \times \frac{\sigma^{2}{ }_{A}}{\sigma_{f m}}+S I_{w f} \times \frac{(t-1)}{t} \times(1-c r) \times \frac{\sigma^{2}{ }_{A}}{\sigma_{w f}}\right)\right\rfloor \\
& \text { and } \Delta G_{m}=\left\lfloor S I_{1} \times c r \times \frac{\sigma_{A}^{2}}{\sigma_{f m}}+S I_{w f} \times \frac{(t-1)}{t} \times(1-c r) \times \frac{\sigma^{2}{ }_{A}}{\sigma_{w f}}\right\rfloor,
\end{aligned}
$$

and the predictions are the predicted genetic gains in the F2 from female and male selection in an F1 population, respectively.

$\left(S I_{1} \quad=\right.$ selection intensity between/among female or male families, respectively, i.e., number of families remaining in seed orchard after roguing of poor families out of the total original number of families,

$S I_{2} \quad=$ selection intensity within female families, i.e., number of families used to make up bulk treatment out of those remaining in seed orchard after roguing,

$\mathrm{cr} \quad=$ coefficient of relationship,

$\sigma_{A}^{2} \quad=$ additive genetic variance, 
$\sigma_{f m} \quad=$ standard deviation between/among families (provenance),

$S I_{w f} \quad=$ selection intensity within female or male families, respectively, within plots,

$t \quad=$ number of trees per plot, and

$\sigma_{w f} \quad=$ within plot family standard deviation).

The selection intensity for male and females differed as, in addition to roguing and thinning, the top 8 to 16 families were selected to make up bulked seed orchard treatments. Male and female selection intensities between/among families and within families within plots were determined using the standardised selection intensity tables of Becker (1975).

The genetic gain equations used for the actual flowering scenarios are similar to those above, except that both the $\Delta G_{f}$ and $\Delta G_{m}$ equations now incorporate the actual number of families flowering, as follows:

$$
\Delta G_{f}=\left\lfloor\left(S I_{1} \times c r \times \frac{\sigma_{A}^{2}}{\sigma_{f m}}+S I_{w f} \times \frac{(t-1)}{t} \times(1-c r) \times \frac{\sigma_{A}^{2}}{\sigma_{w f}}\right)+\left(S I_{3} \times c r \times \frac{\sigma_{A}^{2}}{\sigma_{f m}}+S I_{w f} \times \frac{(t-1)}{t} \times(1-c r) \times \frac{\sigma^{2} A}{\sigma_{w f}}\right)\right\rfloor
$$

and $\Delta G_{m}=\left\lfloor S I_{4} \times c r \times \frac{\sigma_{A}^{2}}{\sigma_{f m}}+S I_{w f} \times \frac{(t-1)}{t} \times(1-c r) \times \frac{\sigma_{A}^{2}}{\sigma_{w f}}\right\rfloor$,

where;

$\mathrm{SI}_{3}=$ selection intensity within female families, i.e., proportion of families selected for the bulk treatment from those flowering in the seed orchard after roguing,

$S_{4} \quad=$ selection intensity within male families, i.e., the proportion of families remaining after roguing multiplied by the proportion of flowering in the seed orchard.

The remainder of the variables are defined as for $\Delta G_{f}$ and $\Delta G_{m}$ in the roguing scenario above. The same additive genetic variances were used for predicting gain from both the rouging and actual flowering (selection) scenarios, after Shelbourne (1992) and other authors (Johnson 1996; Tibbits and Hodge 1998; Volker et al. 1990), where the same variance components were used before and after selection.

The single-site estimates of heritability were used in the genetic gain calculations rather than the general 
across-site heritability estimates, although these can upwardly bias the predicted genetic gain (Tibbits and Hodge 1998). However the authors felt justified in using the single-site estimates because (i) genotypeenvironment effects were negligible in the F1 population, with Type B genetic correlations ranging from 0.75 to 0.99 for the four seed orchards represented in the genetic gain trials (Swain et al. 2013b), with an average genetic correlation of 0.92 , and (ii) the across-site heritability estimate has the disadvantage of losing accuracy with respect to individual site resolution.

\section{Results and discussion}

Comparisons of the predicted gains in dbh from the various scenarios to investigate the underlying assumptions used in estimating genetic parameters for the F1 are presented with the realised gain in Table 1. The data from the individual trials were erratic, and thus the gains were averaged across the trials for each scenario, this approach assumed to be more reliable, and this is summarised in Figure 1. The low predicted gains at Helvetia differed notably from the higher realised gains, due to a particularly low $h^{2}$ for dbh in the F1 ( $h^{2}=0.14$ at 94 months). It is unclear why the $h^{2}$ was so low, relative to the gains, at this site.

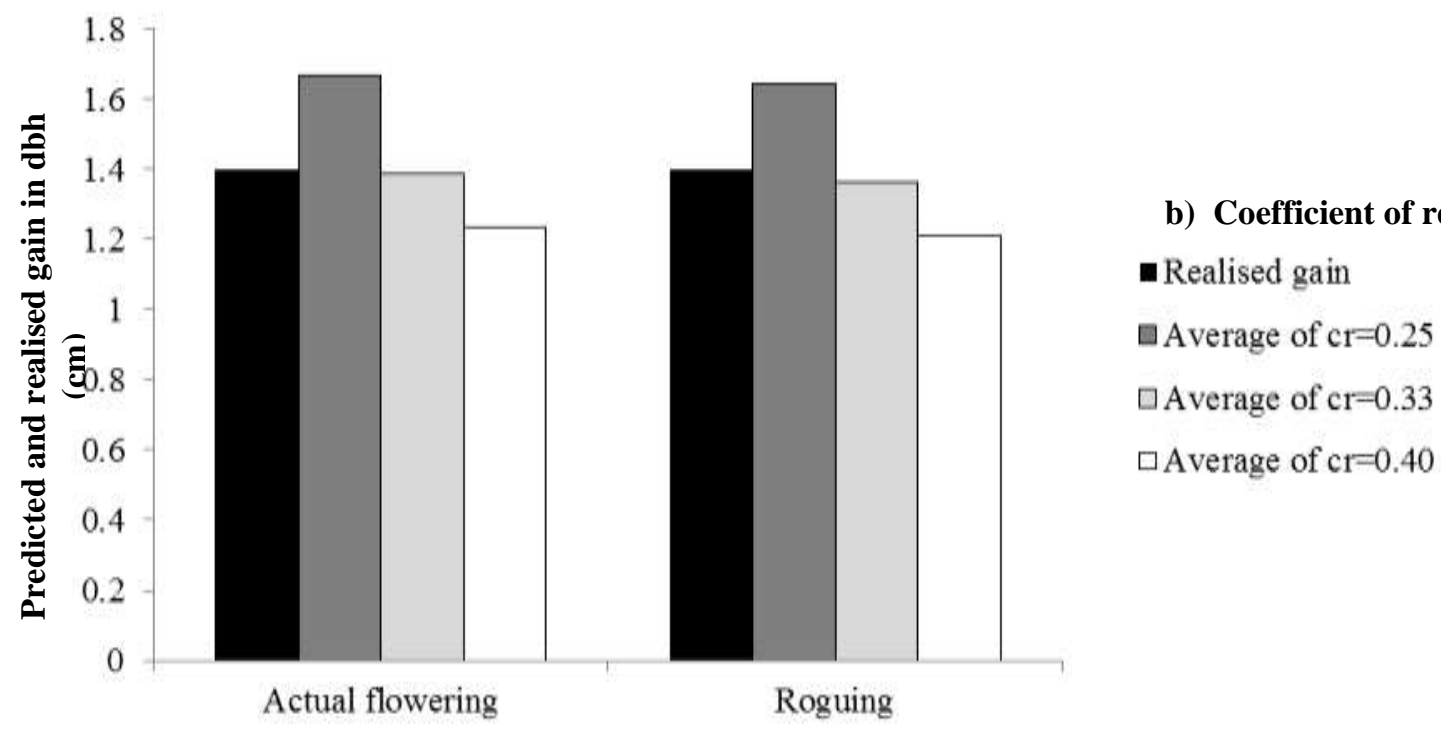

Fig. 1 Comparison of mean ı anscu gan m uun (un) avcragcu auross three Eucalyptus nitens genetic gain trials in South Africa with mean gains predicted from six F1 seed orchards for different scenarios, including; a) Selection Intensity, and b) Coefficient of relationship (cr) 
Table 1 Predicted gains in dbh for various scenarios in F1, compared to realised gains of F2 Eucalyptus nitens bulk treatments at 87 months over unimproved F1 bulk, from six seed orchards, as estimated from genetic gain trials (Swain et al. 2013a)

\begin{tabular}{|c|c|c|c|c|c|c|c|}
\hline & & \multicolumn{6}{|c|}{ Trial series \& site name (age in months at final measurement ${ }^{\mathrm{a}}$ ) } \\
\hline & & $\begin{array}{c}\text { E88/01 } \\
\text { Jessievale } \\
\text { at } 101 \text { mths }(\mathbf{c m}) \\
(\%)\end{array}$ & $\begin{array}{c}\text { E88/01 } \\
\text { Amsterdam } \\
\text { at } 101 \text { mths (cm) } \\
(\%)\end{array}$ & $\begin{array}{c}\mathrm{E88/03} \\
\text { Daspoort } \\
\text { at } 113 \text { mths }(\mathrm{cm}) \\
(\%)\end{array}$ & $\begin{array}{c}\mathbf{E 8 8 / 0 3} \\
\text { Helvetia } \\
\text { at } 94 \text { mths }(\mathrm{cm}) \\
(\%)\end{array}$ & $\begin{array}{c}\text { E88/05 } \\
\text { Babanango } \\
\text { at } 112 \text { mths }(\mathbf{c m}) \\
(\%)\end{array}$ & $\begin{array}{c}\text { E88/06 } \\
\text { Woodstock } \\
\text { at } 76 \text { mths }(\mathrm{cm}) \\
(\%)\end{array}$ \\
\hline \multicolumn{2}{|c|}{ Realised gain in cm dbh (\%) } & $1.02(7.3)$ & $1.90(13.7)$ & $\begin{array}{c}\text { Helvetia bulk }{ }^{\mathrm{b}} \\
1.80(12.9) \\
\end{array}$ & $1.80(12.9)$ & $\begin{array}{c}\text { Jaglust bulk': } \\
1.40 \text { (10.1) }\end{array}$ & $\begin{array}{c}\text { Jaglust bulkc: } \\
1.35(9.7) \\
\end{array}$ \\
\hline Family (provenance) & Scenarios & \multicolumn{6}{|c|}{ Predicted gain in $\mathrm{cm}$ dbh (\% gain) } \\
\hline \multirow[t]{3}{*}{ Roguing: } & $1-c r=0.25$ & $1.17(8.4)$ & $1.84(13.2)$ & $2.47(17.7)$ & $0.35(2.5)$ & $3.00(21.5)$ & $1.84(13.2)$ \\
\hline & $2-c r=0.33$ & $0.99(7.1)$ & $1.25(8.9)$ & $2.05(14.7)$ & $0.32(2.3)$ & $2.52(18.0)$ & $1.55(11.1)$ \\
\hline & $3-c r=0.40$ & $0.89(6.4)$ & $0.94(6.7)$ & $1.82(13.0)$ & $0.31(2.2)$ & $2.26(16.2)$ & $1.40(10.0)$ \\
\hline \multirow[t]{3}{*}{ Actual flowering: } & $4-c r=0.25$ & $1.18(8.5)$ & $1.94(13.9)$ & $2.49(17.8)$ & $0.35(2.5)$ & $3.06(21.9)$ & $1.87(13.4)$ \\
\hline & $5-c r=0.33$ & $1.00(7.1)$ & $1.36(9.7)$ & $2.07(14.8)$ & $0.32(2.3)$ & $2.58(18.4)$ & $1.59(11.3)$ \\
\hline & $6-c r=0.40$ & $0.90(6.4)$ & $1.04(7.4)$ & $1.83(13.1)$ & $0.31(2.2)$ & $2.31(16.6)$ & $1.43(10.2)$ \\
\hline
\end{tabular}

${ }^{a}$ Different ages should be noted,

${ }^{\mathrm{b}}$ As no seed had been produced from this seed orchard by time of F2 establishment, parameters from the related Helvetia orchard were used,

${ }^{\mathrm{c}}$ Jaglust is a seed orchard representing the material in the Babanango and Woodstock trials 


\section{Coefficient of relationship and outcrossing rate}

With regards to the scenarios using actual flowering for family (provenance), which in theory, should be the most accurate predictor of gain, $c r=0.33$ was closest to realised gain (Table 1), indicating the presence of some full-sibs within the open-pollinated F2 families. This was probably mainly as a result of selfing, but possibly also from biparental or neighbourhood mating (Bush et al. 2011). This coefficient of relationship was also found to produce predictions closest to realised values for the roguing scenarios. Although a coefficient of relationship of 0.4 has been used for eucalypts (Brawner and Elizaul 2007; Greaves et al. 1997; Volker et al. 1990; Whiteman et al. 1990), this coefficient of relationship supports earlier work by various authors (Griffin and Cotterill 1988; Griffin et al. 1987; Hodge et al. 1996; Verryn 1993), where it was suggested that seed orchard OP families are not true half-sib families, and may contain sufficient full-sib families to increase the coefficient of relationship from 0.25. A coefficient of relationship of 0.33 has been commonly used by many authors for OP eucalypt populations (Borralho et al. 1992), particularly in South Africa (Louw 1996; Ndlovu 2008; van den Berg and Stanger 2007; van Deventer 2009; Verryn et al. 2009). This coefficient of relationship could be used for future prediction of gains in roguing scenarios in E. nitens, based on our knowledge and the data presented here, and should be sufficient to correct for the amount of selfing or neighbourhood mating taking place. A further consideration however, is whether inbreeding levels are uniform within the entire population, as (i) the application of a single coefficient of relationship to the whole population may not give accurate estimates of variance components, and (ii) in cases where the levels of inbreeding are different from the single coefficient of relationship, the Best Linear Unbiased Predictor (BLUP) breeding values will be improperly regressed towards the mean, which could result in incorrect ranking of breeding values (Bush et al. 2011). Molecular marker studies will further inform the levels of selfing in this population, and whether the levels of inbreeding are variable or more uniform.

In addition, the statistical information suggests that outcrossing was $>80 \%$ in the ICFR seed orchards. This is higher than expected by the authors, given the general sparse flowering in the species in South Africa (Gardner and Bertling 2005; Jones 2002). Hodge et al. (1996) found that estimates of outcrossing in $E$. nitens are higher in seed orchards than in native stands and, following microsatellite studies, Gea et al. 
(2007) estimated an outcrossing rate of 0.87 in an OP E. nitens clonal seed orchard in New Zealand.

Grosser et al. (2010) determined an average outcrossing rate of $85 \%$ in a similar orchard in Australia. Thus these suggestions of higher than expected outcrossing in the ICFR seed orchards are not unreasonable, although such indications would need to be verified with molecular marker studies in this E. nitens population. It is thought that outcrossing is high in E. nitens due to successful late-acting selfincompatibility mechanisms in the species (Hodge and White 1993; Pound et al. 2003).

As variation in the outcrossing rate between families and individuals may obscure differences in breeding values between parents when estimated with OP families (Burgess et al. 1996), it may be worth using family/individual outcrossing rates to better predict breeding values. Hodge et al. (1996), however, found that OP tests predicted breeding values well for E. nitens, and better than for E. globulus.

\section{Selection intensity}

The actual flowering scenarios had similar predicted gains to the roguing scenarios. This was initially surprising due to flowering commonly being poor in E. nitens in South Africa (Gardner 2003; Gardner and Bertling 2005; Jones 2002; Swain and Gardner 2003), with possible subsequent poor outcrossing and genetic gain. A possibility is that the similar predicted gains reflect the low additional selection possible in the orchards due to the low proportion of trees flowering. Further investigation, however, showed that although the proportion of individuals flowering in the ICFR orchards was relatively low in the year prior to the seed collections for the genetic gain trials (15 to $47 \%$ (Swain et al. 2013a)), the total number of families flowering in each seed orchard was generally high (59 to 91\%). As genetic gains are most sensitive to the family selection intensity (as opposed to within family selection) (Shelbourne 1992), this, together with the self-incompatibility mechanisms that exist in E. nitens, may explain the similar predicted gains for the actual flowering and roguing scenarios.

The next logical consideration, i.e., that increased flowering in seed orchards may increase gains due to an increase in population size from which selections are made, bears further consideration. A decrease in outcrossing rates has been linked to a decrease in progeny growth in eucalypts (E. nitens: Hardner and 
Tibbits 1998; E. globulus: Hardner and Potts 1995; Patterson et al. 2004; E. regnans: Griffin and Cotterill 1988), and it has been shown that flowering above a certain low level may result in increased gains (Swain et al. 2013a; Varghese et al. 2009). It is unclear, however, whether additional flowering above this level will confer any further benefit. The flowering levels in the seed orchard bulk entries in the genetic gain trials represent the number of individuals flowering in the seed orchard, irrespective of the number of trees flowering per family, which may be as little as one. A future increase in flowering is most likely to result from more trees per family flowering, rather than a marked increase in the number of families flowering. This is because the number of families flowering in the orchards the year prior to selecting and making up the bulked entries for the genetic gain trials was relatively high (59 to 91\%), compared to the total trees flowering (15 to 47\%) (Swain et al. 2013a). An increase in the number of trees per family flowering would lead to an increase in gain if the best trees per family flowering were selected. Should an increase in the numbers of families flowering be possible in those orchards with less families flowering (e.g. 59\% at Helvetia and $67 \%$ at Jaglust), this, together with selection of the best trees per family flowering, would lead to even greater gains. It is likely that outcrossing would also be improved with increased flowering, resulting in less potential inbreeding depression in the F2.

The numbers of families selected to make up the bulked entries in the genetic gain trials were small and ranged from 8 to 16 families per bulk (Swain et al. 2013a). Although these bulks could certainly be used for establishment of high productivity plantations, it is more likely that, due to the shortage of improved E. nitens seed in South Africa, commercial bulks would comprise at least 16 families. By contrast then, this would mean a decrease in the selection intensity in the seed orchards, with a resultant slight decrease in genetic gain.

Although superior individuals can be grafted from tree improvement trials into clonal seed orchards (CSOs) for capture of maximum genetic gain, problems associated with grafting of E. nitens (de Little et al. 1992; Moncur 1998) can cause delays in production from CSOs, making the South African forestry industry reliant on production of improved seed from Breeding Seed Orchards (BSOs). It is therefore important to construct BSOs with both sufficient families and individuals per family, as well as adequate numbers of 
families flowering simultaneously (or with periods of overlapping flowering), to ensure sufficient outcrossing and to actually realise potential gains. Flowering and seed orchard research that results in technologies to improve and stabilise flowering (Gardner 2012; Germishuizen and Gardner 2014) will help to make this possible.

\section{Provenance effect}

Progeny trials are not generally designed to detect inter-provenance heterosis/non-additive effects (Vaillancourt et al. 1995), yet these effects are likely to be negligible in this population, due to the still significant provenance effect in the F2, the lack of provenance rank changes for dbh in the F2 (Swain et al. 2013a), and the presence of intermediate phenotypes in the F2, indicating a degree of inter-provenance crossing occurring. Although dominance effects have been found in selfed seedlots of E. nitens (Hardner and Tibbits 1998), Hodge et al. (1996) found negligible levels of non-additive effects in their E. nitens study of open-pollinated and control-pollinated progeny, and an absence of inbreeding depression (1\%). These authors also found lower levels of non-additive genetic variation and deleterious abnormalities in E. nitens than in E. globulus (Hodge et al. 1996). Many authors assume negligible or zero non-additive effects in E. nitens (Hamilton et al. 2008).

Although the argument for negligible non-additive effects in this population is strong, the possibility exists that inbreeding depression exists in the ICFR F1 seed orchards due to biparental mating in the native stands. Thus the gains observed in the F2 genetic gain trials (Swain et al. 2013a) may have resulted from changing (decreasing) levels of inbreeding depression due to the release from biparental inbreeding. There is also the slight possibility that provenances themselves are inbred populations, although this seems unlikely, as this has not been reported in the many studies done by various authors on these E. nitens provenances (Gea et al. 1997; Hamilton et al. 2008; Johnson 1996; Tibbits and Hodge 1998; Tibbits and Reid 1987). Molecular studies will better inform both these scenarios.

The significant provenance effect in the F2 (Swain 2013) could be as a result of asynchronous flowering between provenances and resultant lack of panmixis. Asynchronous flowering between provenances in the 
F1 BSOs would violate the assumption that pollination occurs randomly and that pollen parents are equivalent (Shelbourne et al. 2007), and would result in traits and grouping of genes by provenance in the F2. The lack of panmixis would have an effect on the variance components and heritability estimates, with a possible underestimation of family variance components and resultant heritability, if the parents were actually correlated by provenance (Squillace 1974). In addition, given the relatively small population sizes of the seed orchard bulks in the genetic gain trials (F2) and sparse flowering in some of these bulks (Swain et al. 2013a), one could be inclined to raise concerns about the lack of panmixis, which in turn, might lead to inbreeding depression and poorer performances of those bulks.

Although it is difficult to test whether panmixis occurred in these populations without a molecular study, Hodge and White (1993) argued that deviations from panmixis should have little or no effect on the average genetic value of an orchard crop. They suggested that crosses that were absent, or present in unequal frequencies, would only negatively affect overall genetic quality of a seed crop if: a) Specific Combining Ability (SCA) effects are large relative to General Combining Ability (GCA) effects; b) a specific clone crosses more with one or a few clones than with others; and c) the SCA effects of crosses are negative due to the occurrence of a rare event. However, other researchers differ on this point (Grosser et al. 2010; Moncur and Boland 2001; Squillace and Goddard 1982), and maintained that deviations from panmixis can affect the genetic worth of seed. The genetic gain evidence on hand in this study (Swain 2013; Swain et al. 2013a) showed that, barring the seed orchards that had less than $20 \%$ flowering, the observed genetic gains in the F2 population were as expected for a panmictic population.

A further consideration in the estimation of variance components for the prediction of genetic gain is that of competition. Costa e Silva and Kerr (2013) found that variances estimated for additive genetic and residual effects, using models that ignored genetic competition, tended to be biased, which could negatively impact on the total response to selection and thus genetic gain.

Simple family-based models were used to estimate genetic parameters in this study. Although these models currently account for much of the quantitative genetics forest tree literature, many of the assumptions that 
these models rely on are violated in advanced generation tree improvement programmes (White et al. 2007). These assumptions are: 1) Parents must be from the same generation; 2) Parents are unrelated and not inbred; 3) Parents are an unselected random sample from the population; 4) Parents are randomly mated to form the test population; and 5) All parents are mated in a single mating design. Mixed-model methods facilitate analysis of data where different mating designs or highly selected, related and possibly inbred parents from different generations are used, provided that the models are specified correctly and all data are included. In this study, assumptions 1) and 5) were not violated; and 3) and 4) only to the degree that $30 \%$ of the poor families were rogued from the F1 orchards. With regards to assumption 2), it is unlikely that parents were inbred, although there is a possibility of parents being related, due to there being 1 to 10 trees/family remaining in the orchards, albeit at a distance (these distances are greater than $50 \mathrm{~m}$ and can range up to over $100 \mathrm{~m})$. All family-based models, however, are limited in that they do not take into account the pedigree of the trees being tested, i.e., there are no predicted breeding values for each tree measured, only of the parents (White et al. 2007), which are included in individual tree models. By applying a grandmaternal provenance grouping as a fixed effect in the family model, and using various coefficients of relationship for possible relatedness closer than half-sibs in the F2, the simple family-based modelling approach is assumed reasonable in assessing whether predicted genetic gain is in the correct range of realised gain.

The prediction of gain using various scenarios was onerous without the use of a modelling programme, and future modelling of gains in ICFR trials will be done with the assistance of such.

\section{Conclusions}

Parameter estimations using family (provenance) in the F1 E. nitens population resulted in predictions close to the realised gain. A coefficient of relationship of 0.33 appears to fit well in parameter estimation and gain predictions, and should be sufficient for correcting for deviations from half-sib assumptions in the population. Levels of selfing appear to be low $(<20 \%)$, and indications are that levels of outcrossing may be over $80 \%$, despite poor flowering of the species in South Africa. It is clear that molecular studies in the seed orchards and resultant progeny would provide an effective tool to monitor outcrossing rates and the 
role of male and female parents in the orchards, as well as to determine whether panmixis is occurring. This information would allow for refinement of the models over time if necessary.

The stratified or phased selection which is likely taking place in these seed orchards may actually be decreasing gains and thus, in reality, the selection intensities should be revised downwards. This implies that even greater gains are possible if flowering can be increased. It is therefore important firstly, to construct seed orchards with sufficient numbers of families, sufficient individuals per family and adequate numbers of synchronously flowering families; and secondly, to apply technologies to increase flowering, not only to support outcrossing, but also to increase the population size available for selection, such that maximum potential gains can be realised.

Although the progeny trials were not designed to detect inter-provenance heterosis/non-additive effects, they are likely to be negligible in this population. It is suggested, therefore, that it is not necessary to keep provenances separate in current and future ICFR seed orchards, which will make practical management of seed orchards easier.

This study has provided an objective and quantitative assessment of the underlying assumptions used for estimating genetic parameters and predicting gain in this population of E. nitens. It can also be concluded that the assumptions used in the F1 study were correct and no adjustments are necessary to that step in the breeding programme.

\section{Acknowledgments}

Masonite Ltd., Mondi Ltd, NCT Forestry Co-Operative Ltd., PG Bison, TWK Ltd. and York Timbers Ltd. are gratefully acknowledged as funders of this project. 


\section{References}

Becker WA (1975) Manual of Quantitative Genetics. 3rd edn. Washington State University Press, USA

Borralho NMG, Cotterill PP, Kanowski PJ (1992) Genetic parameters and gains expected from selections for dry weight Eucalyptus globulus in Portugal. For Sci 38:80-94

Brawner JT, Elizaul JF (2007) Eucalyptus grandis breeding populations managed for solid wood production in Paraguay and Northern Argentina. In: Upfold S (ed), Proceedings of IUFRO Working Party 2.08.03 Conference, Eucalypts and Diversity: Balancing Productivity and Sustainability, 22-26 October 2007, Durban, South Africa

Burgess IP, Williams ER, Bell JC, Harwood CE, Owen JV (1996) The effect of outcrossing rate on the growth of selected families of Eucalyptus grandis. Silvae Genet 45(2-3):97-100

Bush D, Kain D, Matheson C, Kanowski P (2011) Marker-based adjustment of the additive relationship matrix for estimation of genetic parameters - an example using Eucalyptus cladocalyx. Tree Genet Genome 7:23-25. DOI $10.1007 / \mathrm{s} 11295-010-0312-\mathrm{z}$

Butcher PA, Williams ER (2002) Variation in outcrossing rates and growth in Eucalyptus camaldulensis from the Petford Region, Queensland; evidence of outbreeding depression. Silvae Genet 51:6-12

Callister AN, England N, Collins S (2013) Predicted genetic gain and realised gain in stand volume of Eucalyptus globulus. Tree Genet \& Genome 9, 361-375

Costa e Silva J, Kerr RJ (2013) Accounting for competition in genetic analysis, with particular emphasis on forest genetic trials. Tree Genetics \& Genomes 9, 1-17

de Little DW, Tibbits WN, Rasmussen GF, Ravenwood I (1992) Genetic improvement strategy for APPM Eucalypt tree farms in Tasmania. In: ACTES proceedings, Bordeaux, Mass Production Technology for Genetically Improved Fast Growing Forest Tree Species. 14-18 September 1992. AFOCEL (Association Foret Cellulose), Nangis, France

Falconer DS, Mackay TFC (1996) Introduction to Quantitative Genetics. 4th edn, Longman Group Ltd., England 
Gardner RAW (2003) Floral induction in Eucalyptus nitens (Deane \& Maiden) Maiden in South Africa. MSc thesis, University of Natal, Pietermaritzburg, South Africa

Gardner RAW (2012) Flowering Research in Cold Tolerant Eucalypts. ICFR Annual Research Review 2011. Institute for Commercial Forestry Research, Pietermaritzburg, South Africa

Gardner RAW, Bertling I (2005) Effect of winter chilling and paclobutrazol on floral bud production in Eucalyptus nitens. S Afr J Bot 71(2): 238-249

Gardner RAW, Swain T-L (1996) Snow damage to timber plantations in KwaZulu-Natal during July 1996 and subsequent species recommendations. ICFR Bulletin Series No. 08/1996. Institute for Commercial Forestry Research, Pietermaritzburg

Gea LD, McConnochie R, Hong M, Shelbourne CJA (1997) Variance component differences for first and second generation E. nitens progenies. In: Higa AR, Schaitza E, Gaiad S (eds), Proceedings of IUFRO Working Group 2.08.03 Conference, Silviculture and Improvement of Eucalypts, 24-29 August 1997, Salvador, Brazil

Gea LD, McConnochie R, Wynyard S (2007) Parental reconstruction for breeding deployment, and seed orchard management of Eucalyptus nitens. NZ J For Sci 37(1):23-36

Germishuizen I, Gardner RAW (2014) A mapping tool for the siting of Eucalyptus nitens seed orchards based on climate. South For (in press)

Greaves BL, Borralho NMG, Raymond CA, Evans R, Whiteman PH (1997) Age-age correlations in and relationships between basic density and growth in Eucalyptus nitens. Silvae Genet 46(5):264-270.

Griffin AR, Moran GF, Fripp YJ (1987) Preferential outcrossing in Eucalyptus regnans F. Muell. Aus J Bot 35:465-475

Griffin AR, Cotterill PP (1988) Genetic variation in growth of outcrossed, selfed and open-pollinated progenies of Eucalyptus regnans and some implications for breeding strategy. Silvae Genet 37(3-4):124-131 
Grosser G, Potts BM, Vaillancourt RE (2010) Microsatellite based paternity analyses in a clonal Eucalyptus nitens seed orchard. Silvae Genet 59 (2-3):57-62

Hamilton MG, Joyce K, Williams D, Dutkowski G, Potts B (2008) Achievements in forest tree improvement in Australia and New Zealand 9. Genetic improvement of Eucalyptus nitens in Australia. Aus For 71(2):82-93

Hardner CM, Potts BM (1995) Inbreeding depression and changes in variation after selfing Eucalyptus globulus subsp. globulus. Silvae Genet 44:46-54

Hardner C, Tibbits W (1998) Inbreeding depression for growth, wood and fecundity traits in Eucalyptus nitens. For Genet 51:11-20

Hodge GR, White TL (1993) Advanced-generation wind-pollinated seed orchard design. New For 7:213-236

Hodge GR, Volker PW, Potts BM, Owen JV (1996) A comparison of genetic information from open-pollinated and control-pollinated progeny tests in two eucalypt species. Theore Appl Genet 92:53-63

Johnson IG (1996) Growth and form of Eucalyptus nitens progenies in New South Wales, and selection strategies for a seedling seed orchard. Aust For 59(4):162-170

Jones WR (2002) Breeding Systems of Some Cold Tolerant Eucalyptus Species. MSc thesis, University of Natal, Pietermaritzburg, South Africa

King JN, Wilcox MD (1988) Family tests as a basis for the genetic improvement of Eucalyptus nitens in New Zealand. NZ J For Sci 18:253-266

Kunz R, Gardner RAW (2001) A review of factors affecting snow damage of commercial forest plantations in South Africa. ICFR Bulletin Series No. 13/2001. Institute for Commercial Forestry Research, Pietermaritzburg 
Littell RC, Milliken GA, Stroup WW, Wolfinger RD (1996) SAS System for Mixed Models. SAS Institute Inc, Cary, NC, USA

Leal AM, Cotterill PP (1997) Mass controlled pollination of Eucalyptus globulus. In: Higa AR, Schaitza E, Gaiad S (eds), Proceedings of IUFRO Working Group 2.08.03 Conference, Silviculture and Improvement of Eucalypts, 24-29 August 1997, Salvador, Brazil

Louw AK (2006) Investigation of the application of best linear prediction for breeding and clonal production purposes in a Eucalyptus grandis population. MSc thesis, University of KwaZulu-Natal, Pietermaritzburg, South Africa

Moncur MW (1998) Hastening seed production: a tool for increasing the rate of genetic improvement in eucalypt species. In: Puri S (ed.), Tree Improvement: Applied Research and Technology Transfer. Science Publishers Inc, USA

Moncur MW, Boland DJ (2001) Production of genetically improved Eucalyptus nitens seed for reforestation. Aust For 63(3):211-217

Moncur MW, Hasan O (1994) Floral induction in Eucalyptus nitens (Deane and Maiden) Maiden. Tree Physiol 14:1303-1312

Moncur MW, Mitchell A, Fripp Y, Kleinschmidt GJ (1995) The role of honey bees (Apis mellifera) in eucalypt and acacia seed production areas. Can J For Res 24:46-49

Moran GF, Bell JC, Griffin AR (1989) Reduction in levels of inbreeding in a seed orchard of Eucalyptus regnans F. Muell. compared with natural populations. Silvae Genet 38(1):32-36

Ndlovu ZTL (2009) Breeding of advanced generation of Eucalyptus macarthurii - growth parameters and development of a non-destructive near infrared (NIR) calibration model for screening of pulping properties. MSc thesis, University of KwaZulu-Natal, Pietermaritzburg, South Africa

Patterson B, Vaillancourt RE, Pilbeam DJ, Potts BM (2004) Factors affecting variation in outcrossing rate in Eucalyptus globulus. Aus J Botany 52:773-780 
Pound LM, Wallwork MAB, Potts BM, Sedgley M (2003) Pollen tube growth and early ovule development following self- and cross-pollination in Eucalyptus nitens. Sex Plant Prop 16:59-69

Raymond CA, Schimleck LR, Muneri A, Michell AJ (2001) Genetic parameters and genotype-by-environment interactions for pulp yield predicted using near infrared reflectance analysis and pulp productivity in Eucalyptus globulus. For Genet 8(3):213-224

Shelbourne CJA (1992) Genetic gains from different kinds of breeding population and seed or plant production populations. S Afr For J 160:49-65

Shelbourne CJA, Kumar S, Burdon RD, Gea LD, Dungey HS (2007) Deterministic simulation of gains for seedling and cloned main and elite breeding populations of Pinus radiata and implications for strategy. Silvae Genet 56(6):259-270

Squillace AE (1974) Average genetic correlations among offspring from open pollinated forest trees. Silvae Genet 23(5):149-156

Squillace AE, Goddard RE (1982) Selfing in clonal seed orchards of slash pine. For Sci 28(1):71-78

Snedden CL, Roux CZ, Verryn SD (2007) Broad and narrow sense heritabilities in a South African cloned openpollinated Eucalyptus grandis breeding population. South Hemisph For J 69(2):81-90

Suitor S, Potts BM, McGowen MH, Pilbeam DJ, Brown PH, Gracie AJ, Gore PL (2009) The relative contribution of the male and female to the variation in reproductive success in Eucalyptus globulus. Silvae Genet 58(3):129-138

Swain T-L (2013) Development of an advanced generation breeding strategy for Eucalyptus nitens (Deane and Maiden) Maiden. PhD thesis, University of KwaZulu-Natal, Pietermaritzburg, South Africa

Swain T-L, Gardner RAW (2003) A summary of current knowledge of cold tolerant eucalypt species (CTE's) grown in South Africa. ICFR Bulletin No. 03/2003. Institute for Commercial Forestry Research, Pietermaritzburg 
Swain T-L, Verryn SD, Laing MD (2013a) A comparison of the effect of genetic improvement and seed source and seedling seed orchard variables on progeny growth in Eucalyptus nitens in South Africa. Tree Genet Genome 9(3):767778. DOI 100.1007/ s11295-013-0593-0

Swain T-L, Verryn SD, Laing MD (2013b) Genetic characterisation of a Eucalyptus nitens base breeding population in South Africa. South For 75(3): 155-167. DOI 10.2989/ 20702620.2013.823717

Tibbits WN (1989) Controlled pollination studies with Shining Gum (Eucalyptus nitens (Deane \& Maiden) Maiden). Forestry 62(2):111-126

Tibbits W, Hodge G (1998) Genetic parameters and breeding value predictions for Eucalyptus nitens wood fibre production traits. For Sci 44(4):587-598

Tibbits WN, Reid JB (1987) Frost resistance in Eucalyptus nitens (Deane \& Maiden) Maiden: Genetic and seasonal aspects of variation. Aust For Res 17:29-47

Vaillancourt RE, Potts BM, Watson M, Volker PW, Hodge GR, Reid JB, West AK (1995) Detection and prediction of heterosis in Eucalyptus globulus. For Genet 2(1):11-19

van den Berg GJ, Stanger TK (2007) Tree volume, survival and basic wood density results for seven year old second generation Eucalyptus nitens. In: Upfold S (ed), Proceedings of IUFRO Working Party 2.08.03 Conference, Eucalypts and Diversity: Balancing Productivity and Sustainability, 22-26 October 2007, Durban, South Africa

van Deventer F (2009) A quantitative study on growth, basic wood density and pulp yield in a breeding population of Eucalyptus urophylla S.T. Blake, grown in KwaZulu-Natal. MSc thesis, University of Natal, Pietermaritzburg, South Africa

Varghese M, Kamalakannan R, Harwood CE, Lindgren D, McDonald MW (2009) Changes in growth performance and fecundity of Eucalyptus camaldulensis and E. tereticornis during domestication in southern India. Tree Genet Genome 5:629-640 
Verryn SD, Snedden CL, Eatwell KA (2009) A comparison of deterministically predicted genetic gains with those realised in a South African Eucalyptus grandis breeding program. South For 71(2):141-146

Verryn SD, Snedden CL, Parfitt RC (2000) Program for the deterministic modelling of genetic gains of tree breeding and seed and clone production strategies. S Afr For J 189:3-9

Volker PW, Dean CA, Tibbits WN, Ravenwood IC (1990) Genetic parameters and gains expected from selection in

Eucalyptus globulus in Tasmania. Silvae Genet 39(1):18-21

White TL (1987) A conceptual framework for tree improvement programs. New For 4:325-342

Whiteman PH, Dean CA, Doran JC, Cameron JN (1992) Genetic parameters and selection strategies for Eucalyptus nitens (Deane and Maiden) in Victoria. Silvae Genet 41:77-81 